\title{
EVALUASI INSTALASI PENGOLAHAN AIR LIMBAH (IPAL) UNIVERSITAS SEBELAS MARET SURAKARTA
}

\author{
Ayu Ismoyo Sofiana1), Budi Utomo'), Sudarto ${ }^{3)}$ \\ 1) Mahasiswa Jurusan Teknik Sipil,Universitas Negeri Sebelas Maret \\ 2),3) Pengajar Jurusan Teknik Sipil,Universitas Negeri Sebelas Maret \\ Jl. Ir Sutami 36 A, Kentingan Surakarta 57126; Telp 0271-634524. Fax 662118 \\ Email: ayuismoyosofiana@gmail.com
}

\begin{abstract}
Ayu Ismoyo Sofiana, Budi Utomo, Sudarto, 2017. Installation Evaluation of Waste Water Treatment.(IPAL/InstalasiPengolahan Air Limbah) in the Area of Sebelas Maret University of Surakarta.Research paper. Civil Engineering Study Program.Faculty of engineering.Sebelasmaret University of Surakarta.

Jebres district is a dense district which is hasjust installed waste water treatment (IPAL). That area is located at Sebelas Maret University of Surakarta. IPAL UNS serves all toilet at Sebelas Maret University, houses and general building at district $\mathrm{R} W 10-14$, Jebres.

This research tests quality and quantity in IPAL by calculating the work efficiency, field waste water discharger, and age testing of IPAL UNS. The test of work efficiency by measuring field volume is done on IPAL effluent and laboratory testing of waste water sample with chemistry and physic parameter; physic parameter is TSS and temperature, while chemistry parameter is $p H, C O D$ and BOD. Beside, the calculation of IPAL age comparison between water discharger from questioner's way and water dischargerfrom standart water usage.

From the result of IP AL operational system research, it is obtained field water discharger 3,0048 liter/second with work efficiency from IPAL with each parameter is TSS 52,69\%, BOD 74,46\% and COD permanganant nominal 49,75\% so that IPAL's work efficiency is not equal with criteria design of IPAL. Besides, the average of waste water discharger from quesioner is 4,854 liter/second and standart water usage is 5,5334 liter/second. By using quesioner of waste water discharger, obtained IPAL age is 24 years in the year of 2041. And by using standart waterusage, obtained IPAL age is 21 years in the year of 2038.
\end{abstract}

Keywords : IPAL UNS, quality, water discharger efficency, age

\begin{abstract}
Abstrak
Kelurahan Jebres adalah kelurahan padat penduduk yang baru saja terpasang Instalasi Pengolahan Air Limbah (IPAL) Kawasan yang terletak di Universitas Sebelas Maret Surakarta.IPAL Kawasan UNS melayani seluruh kamar kecil yang ada di Universitas Sebelas Maret dan rumah-rumah serta bangunan umum di wilayah RW 10-14 Kelurahan Jebres.

Penelitian ini menguji faktor kualitas dan kuantitas yang ada pada IPAL dengan menghitung efisiensi kinerja, debit air buangan lapangan, dan pengujian umur.Pengujian efisiensi kinerja dengan cara pengukuran debit lapangan dilakukan pada efluen IPAL dan pengujian laboratorium sampel air limbah dengan parameter fisika dan kimia yaitu parameter fisika TSS dan suhu, sedangkan parameter kimiayaitu $\mathrm{pH}, \mathrm{COD}$,dan BOD. Selain itu dilakukan perhitungan umur IPAL dengan cara dibandingkan perolehan debit dengan cara kuesioner dan dengan cara standar pemakaian air. Dari hasil penelitian sistem operasional IPAL tersebut didapatkan hasil berupa debit lapangan sebesar 3,0048 liter/detik serta efisiensi kinerja dari IPAL masing-masing parameter adalah TSS 52,69 \% , BOD 74,46 \%,dan COD Angka Permanganat 49,75\% sehingga efisiensi kinerja IPAL tidak sesuai dengan desain kriteria IPAL. Selain itu debit air buangan rata-rata dari kuesioner sebesar 4,854 liter/detik dan debit air buangan dari standar pemakaian air sebesar 5,5334 liter/detik. Dengan menggunakan debit air buangan kuesioner didapat umur IPAL sebesar 24 tahun pada tahun 2041. Dan dengan menggunakan debit air buangan standar pemakaian air didapat umur IPAL sebesar 21 tahun pada tahun 2038.
\end{abstract}

Kata kunci : IPAL UNS,kualitas,debit air,efisiensi,umur 


\section{PENDAHULUAN}

Di setiap gedung UNS menggunakan sistem pembuangan on site yaitu pembuangan yang dialirkan ke septic tank dengan pengurasan berkala, sedangkan di bagian limbah kamar mandi, mencuci, tempat ibadah disalurkan langsung tanpa pengolahan menuju saluran drainase UNS dimana saluran itu juga menerima limbah yang berasal dari warga di beberapa wilayah di kelurahan Jebres dan Kampus ISI. Oleh sebab itu, dapat memperburuk kualitas Sungai Bengawan Solo sebagai badan air penerima dari saluran drainase UNS. Padahal air Sungai Bengawan Solo saat ini sudah digunakan bahan pengolahan sumber air baku bagi masyarakat dikala kebutuhan sumber air bersih meningkat. Dari permasalahan itu Kementrian Pekerjaan Umum dan Dirjen Cipta Karya mencanangkan sistem pengolahan air limbah kawasan untuk mengolah limbah yang berada di wilayah Universitas Sebelas Maret Surakarta. Dengan adanya IPAL Kawasan UNS membantu IPA (Instalasi Pengolahan Air) yang berada di wilayah Sungai Bengawan Solo pengoperasiannya menjadi lebih efisien. Saat ini IPAL Kawasan Universitas Sebelas Maret sudah selesai dibangun dan mulai dioperasikan pada tanggal 21 Desember 2016. Beroperasinya IPAL UNS ini masih ada permasalahan lapangan yaitu masih terjadi penyumbatan di pipa,pada saat ini sebagian warga belum terlayani, dan hasil pengolahan masih ada bau. Oleh sebab itu, dilakukan evaluasi penelitian sistem operasional IPAL UNS berupa umur pelayanan, debit buangan air limbah, dan efisiensi kinerja pada IPAL UNS.

Berdasarkan latar belakang masalah tersebut maka dapat dirumuskan masalah Berapak efisiensi kinerja IPAL kawasan di UNS, debit air buangan dari penduduk, mahasiswa, karyawan dan dosen pengguna IPAL UNS, dan umur pelayanan IPAL kawasan yang berada di UNS.

\section{TINJAUAN PUSTAKA DAN LANDASAN TEORI}

Menurut Permen Pekerjaan Umum No.16/PRT/M/2008 visi dari penyelenggaraan air buangan pemukiman adalah untuk mencapai kondisi masyarakat hidup sehat dan sejahtera dalam lingkungan yang bebas dari pencemaran air buangan permukiman di masa yang akan datang, baik yang berada di daerah perkotaan maupun yang tinggal di daerah pedesaan, memerlukan pengelolaan air buangan pemukiman yang memadai, yang dapat melindungi sumber-sumber air baku bagi air minum dari pencemaran pembuangan air buangan.

\section{Baku Mutu Air}

Baku mutu air buangan domestik adalah batas/kadar unsur pencemar atau jumlah unsur pencemar yang ditenggang keberadaannya dalam air buangan domestik yang akan dilepas ke air permukaan.

Berdasarkan Permen Menteri Lingkungan Hidup dan Kehutanan No.P.68/Menlhk/Setjen/Kum.1/8/2016 tentang baku mutu air buangan domestic dan Peraturan Daerah Provinsi Jawa Tengah No.5 Tahun 2012 tentang baku mutu air buangan.

\section{Kebutuhan Air Domestik atau Rumah Tangga}

Standar kebutuhan air domestik yaitu kebutuhan air bersih pada tempat- tempat hunian pribadi untuk memenuhi keperluan sehari-hari, antara lain untuk memasak, minum, mencuci dan keperluan rumah tangga lainnya. Satuan yang dipakai adalah liter/orang/hari.

\section{Kebutuhan Air Non Domestik}

Kebutuhan air non domestik berasal dari industri, baik pengolahan dan pemrosesan industri,dan bangunan komersial lainnya seperti tempat peribadatan,swalayan,dan sekolah. Kebutuhan Air Non Domestik diatur dalam SNI No 03-7065-2005.

\section{Fluktuasi Debit Air Buangan}

Fluktuasi debit air buangan dapat berbeda pada waktu-waktu tertentu karena beberapa faktor. Fluktuasi debit air buangan disebabkan oleh jam-jam puncak pemakaian,hari-hari puncak pemakaian,dan faktor infiltrasi dan inflow.(Moduto, 2000)

Teknik Pengambilan Sampel 
Populasi adalah keseluruhan subjek yang menjadi sasaran penelitian yang mempunyai karakteristik tertentu. Sedangkan sampel adalah sejumlah (tidak semua) hal yang diobservasi/diteliti yang relevan dengan masalah penelitian,dan tentunya subjek atau objek yang diteliti tersebut.(Rostina Sundayana,2015)

Teknik sampling adalah teknik pengambilan sampel. Untuk menentukan sampel yang akan digunakan dalam penelitian,terdapat berbagai teknik sampling yaitu berbagai macam probability sampling dan nonprobability sampling. (V Wiratna Sujarweni,2014)

\section{Metode Proyeksi Pertumbuhan Penduduk}

Metode linear aritmatik adalah metode proyeksi yang paling sederhana dari seluruh metode yang ada dengan menggunakan persamaan derajat pertama (first degree equation). Oleh sebab itu, penduduk diproyeksikan sebagai fungsi dari waktu. Hasil proyeksi pada metode ini akan membentuk suatu garis lurus.

Metode Geometrik adalah metode yang mengasumsikan penduduk bertambah/berkurang pada suatu tingkat pertumbuhan (persentase) yang tetap. Proyeksi dengan tingkat pertumbuhan yang tetap ini umumnya dapat diterapkan pada wilayah, dimana pada tahun-tahun awal observasi pertambahan absolut penduduknya sedikit dan menjadi semakin banyak pada tahun-tahun akhir.

\section{Rumus Pengambilan Sampel}

Rumus pengambilan sampel digunakan untuk menentukan jumlah sampel penelitian. Pada prinsipnya penggunaan rumus pengambilan sampel penelitian digunakan untuk mempermudah teknis penelitian sebagai suatu cara untuk mencari jumlah sampel seminimal dan seakurat mungkin di lokasi yang luas. Berikut beberapa rumus untuk pengambilan sampel dalam penelitian yaitu rumus Slovin dan rumus Isaac dan Michael. (V Wiratna Sujarweni,2014)

\section{METODE PENELITIAN}

Metode penelitian berupa penelitian evaluasi dan non eksperimental. Lokasi penelitian IPAL berada di kawasan UNS dengan daerah pelayanan IPAL adalah RW 10-14 Kelurahan Jebres dan Universitas Sebelas Maret. Pada penelitian evaluasi ipal memiliki beberapa tahapan pengerjaan sebagai berikut.

1. Pengumpulan data primer berupa pengukuran debit air buangan lapangan IPAL di effluent Biopods Ponds .

2. Pengumpulan data primer berupa sampel air buangan sebanyak tiga kali untuk uji laboratorium.

3. Uji laboratorium sampel air buangan dengan parameter BOD, COD, TSS, dan $\mathrm{NH}_{3}$.

4. Membandingkan hasil uji laboratorium dengan standar pemerintah Indonesia.

5. Menghitung efisiensi kinerja masing-masing parameter $\mathrm{BOD}$, COD, TSS, dan $\mathrm{NH}_{3}$.

6. Pengumpulan data sekunder berupa jumlah mahasiswa, dosen, karyawan dan penduduk pada kurun waktu 2012-2016.

7. Pengumpulan data primer berupa kuesioner kebutuhan air bersih pada civitas akademika UNS dan warga RW 10-RW 14 Kelurahan Jebres,

8. Menghitung proyeksi dan pertumbuhan penduduk selama 45 tahun.

9. Menghitung fluktuasi dan debit air buangan yang berasal dari kuesioner dan standar pemakaian air sebagai pembanding.

10. Menghitung umur tiap tanki dengan debit yang berasal dari kuesioner dan debit dari standar pemakaian air sebagai pembanding

11. Membandingkan hasil perhitungan umur dari debit kuesioner dan debit dari standar pemakaian air.

HASIL DAN PEMBAHASAN

Efisiensi Kinerja Pengolahan IPAL UNS 


\section{Pengukuran Debit Lapangan}

Pengukuran dilakukan di effluen Biopods Ponds selama 24 jam dalam satu hari,pada tanggal 19 Juni 2016. Gambar pengukuran dan fluktuasi hasil pengujian debit lapangan dapat dilihat Gambar 1.

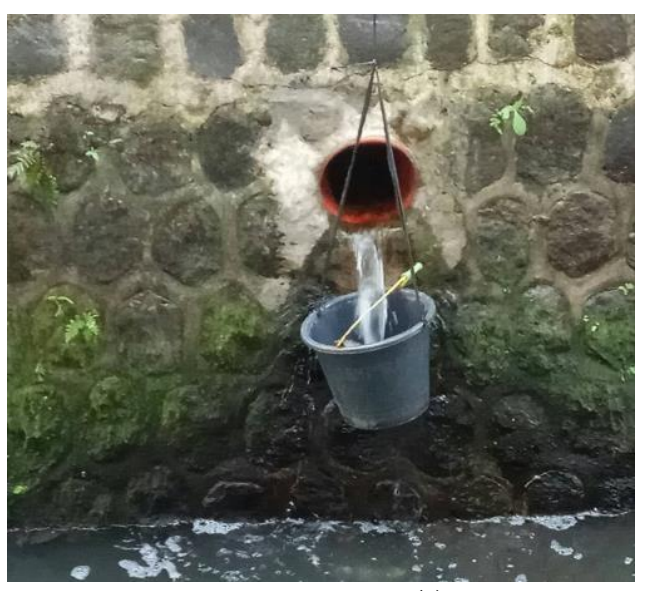

(a)

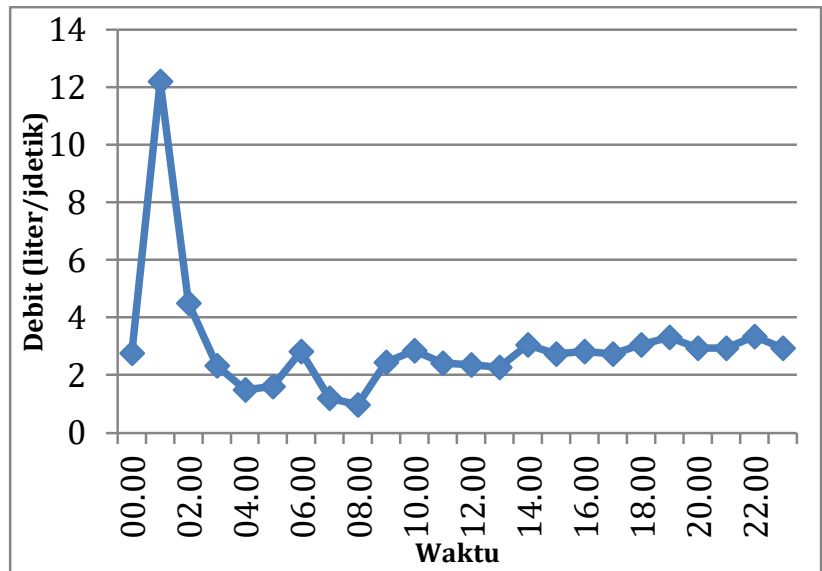

(b)

Gambar 1. (a) Pengukuran Debit Air Lapangan (b),Fluktuasi Debit Air Buangan Lapangan

Dari grafik fluktuasi debit air buangan tersebut didapatkan bahwa debit air buangan terbesar terjadi di pukul 01.00 sebesar 12,195 liter/detik,serta debit air buangan terkecil terjadi di pukul 08.00 sebesar 0,9798 liter/detik.

\section{Pengujian Kualitas Air Buangan Bagian Inlet dan Outlet}

Penelitian kualitas air buangan dilakukan pengambilan sampel sebanyak 3 kali di pagi hari. Pengambilan sampel dilakukan di inlet dan outlet IPAL tersebut, bagian inlet IPAL yaitu Bak Pengumpul dan bagian outlet IPAL yaitu Bak Sedimen II.Pengujian sampel di lakukan di Laboratorium Penyehatan. Hasil pengujian dilihat pada Tabel 1

Tabel 1. Rata-Rata Hasil Pengujian Laboratorium Tiga Hari Sampel

\begin{tabular}{|c|c|c|c|c|c|}
\hline \multirow[t]{2}{*}{ No. } & \multirow[t]{2}{*}{ Parameter } & \multirow[t]{2}{*}{ Satuan } & \multicolumn{2}{|c|}{ Hasil Pengujian } & \multirow{2}{*}{$\begin{array}{c}\text { Metode } \\
\text { Pengujian }\end{array}$} \\
\hline & & & Inlet & Outlet & \\
\hline \multicolumn{6}{|c|}{ Parameter Fisika } \\
\hline 1. & Suhu & ${ }^{\circ} \mathrm{C}$ & 28,67 & 28,67 & $\begin{array}{l}\text { SNI 06-6989.23- } \\
2005\end{array}$ \\
\hline 2. & TSS & $\mathrm{mg} /$ liter & 62 & 29,33 & $\begin{array}{l}\text { SNI 06-6989.3- } \\
2004\end{array}$ \\
\hline \multicolumn{6}{|c|}{ Parameter Kimia } \\
\hline 1. & $\mathrm{Ph}$ & - & 5,67 & 7 & $\begin{array}{l}\text { SNI 06-6989.11- } \\
2004\end{array}$ \\
\hline 2. & $\mathrm{BOD}_{5}$ & $\mathrm{mg} /$ liter & 35,416 & 9,044 & $\begin{array}{l}\text { SNI 6989.72- } \\
2009\end{array}$ \\
\hline 3. & $\begin{array}{c}\text { COD } \\
\text { Permanganat }\end{array}$ & $\mathrm{mg} /$ liter & 168,533 & 84,688 & SNI 6989.2-2009 \\
\hline
\end{tabular}

Hasil pengujian laboratorium tersebut dibandingkan dengan Permen Menteri Lingkungan Hidup dan Kehutanan No.P.68/Menlhk/Setjen/Kum.1/8/2016 tentang baku mutu air limbah domestik dan Peraturan Daerah Provinsi Jawa Tengah No.5 Tahun 2012 tentang baku mutu air limbah . Berikut perbandingan hasil pengujian dengan dua standart pemerintah tersebut pada Gambar 2. 


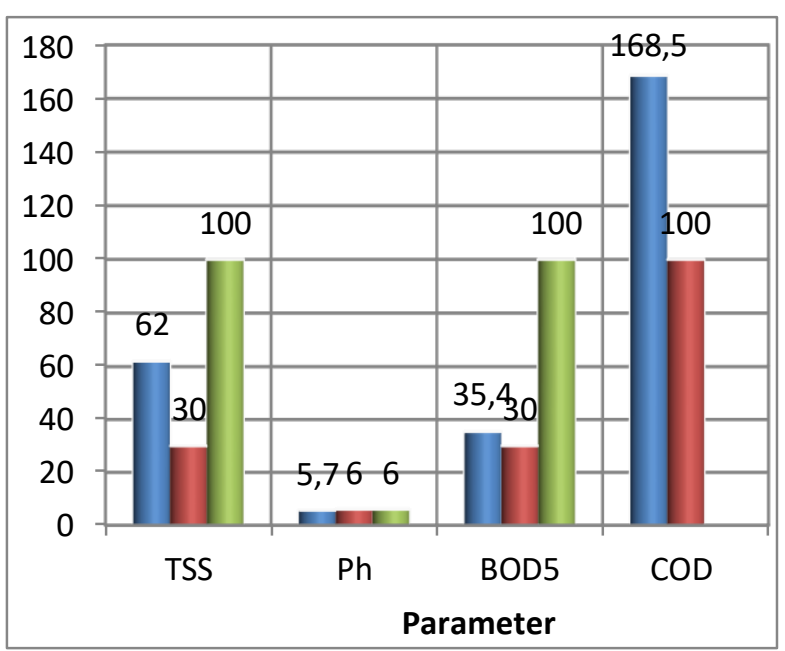

(a)

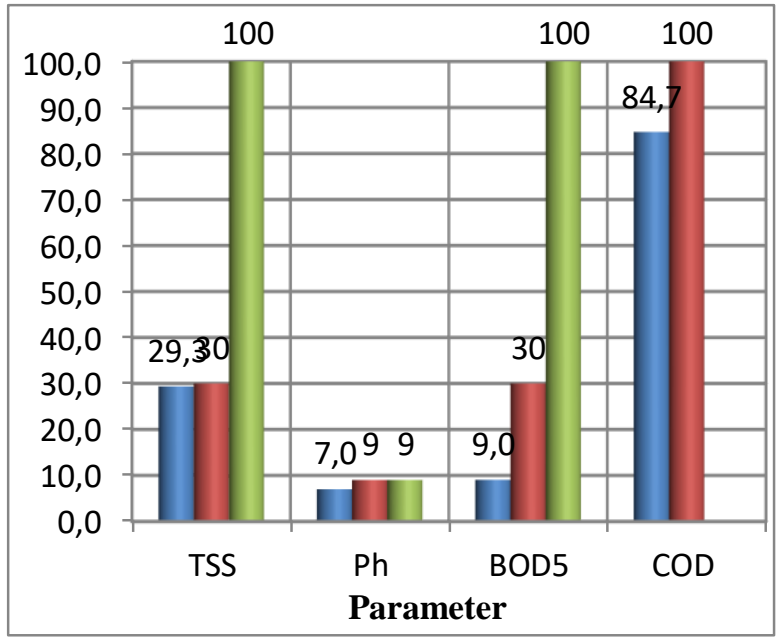

(b)

Gambar 2.(a) Perbandingan Hasil Pengujian Inlet Rata-Rata dengan Peraturan Pemerintah (b), Perbandingan Hasil Pengujian Outlet Rata-Rata dengan Peraturan Pemerintah

Dari gambar 2 (a) dapat diambil kesimpulan bahwa air limbah yang berasal dari kawasan Universitas Sebelas Maret dan Kelurahan Jebres khususnya RW 10-14 belum memenuhi standar untuk dibuang ke badan air penerima sehingga membutuhkan sistem pengolahan limbah. Dari gambar 2 (b) didapat bahwa hasil pengujian pada bagian outlet sudah memenuhi dengan kedua standar pemakaian air tersebut.

Dari perhitungan nilai efisiensi dari perhitungan data diperoleh nilai TSS yaitu 52,69 \% dan BOD sebesar 74,45 \% sedangkan untuk nilai COD Angka Permanganat sebesar 49,76 \%. Dalam efisiensi tersebut tidak semuanya memiliki efisiensi diatas $50 \%$ menunjukkan bahwa sistem pengolahan secara aerob-anaerob pada IPAL Kawasan Universitas Sebelas Maret berlangsung tidak baik.

\section{Perhitungan Umur IPAL}

\section{Perhitungan Umur dengan Cara Kuesioner}

Nilai penggunaan air untuk pada pengguna IPAL dihitung berdasarkan petunjuk teknis dari Syed R Qasim,1985 dimana jumlah penduduk kurang dari 20.000 orang sehingga dapat disimpulkan bahwa kebutuhan air domestik rata-rata 100 liter/orang/hari. Sedangkan untuk rincian penggunaan air pada masing-masing kegiatan manusia menggunakan standart dari Fair dkk,1971.Berikut contoh perhitungan penggunaan air bersih perpemakaian.

Mandi $=$ kebutuhan air domestik $\times$ persentase mandi

$$
\begin{aligned}
& =100 \text { liter/orang/hari } \times 34 \% \\
& =34 \text { liter/orang/hari }
\end{aligned}
$$

Berikut rekapitulasi penggunaan air bersih pada perpemakaian pada tabel 2 .

Tabel 2. Asumsi Penggunaan Air Bersih Perpemakaian

\begin{tabular}{llcc}
\hline No. & $\begin{array}{c}\text { Aspek } \\
\text { Penilaian }\end{array}$ & $\begin{array}{c}\text { Penggunaan Air Bersih } \\
\text { Per Pemakaian (liter/hari) }\end{array}$ & $\begin{array}{c}\text { Jumlah } \\
\text { Pemakaian } \\
\text { Perhari }\end{array}$ \\
\hline 1 & Mandi & 34 & Satu hari 2 kali \\
\hline 2. & Buang Air Kecil & 31,2 & Satu hari 6 kali \\
\hline 3. & Buang Air Besar & 10,3 & Satu hari sekali \\
\hline 4. & $\begin{array}{l}\text { Cuci Piring atau } \\
\text { kegiatan dapur }\end{array}$ & 6 & Satu hari sekali \\
\hline 5. & Cuci Pakaian & 9 & Satu hari sekali \\
\hline 6. & Wudhu & 15 & Satu hari 5 kali \\
\hline \multicolumn{2}{l}{ Total Kebutuhan Air } & 105,5 & \\
\hline
\end{tabular}

Perhitungan sampel menggunakan rumus Isaac dan Michael sehingga didapat hasil sampel pada 
kuesioner berjumlah 275 sampel masing-masing 225 sampel mahasiswa,22 sampel warga, 13 sampel dosen,dan 15 sampel karyawan. Hasil perhitungan umur dengan cara kuesioner dapat dilihat pada Gambar 3.

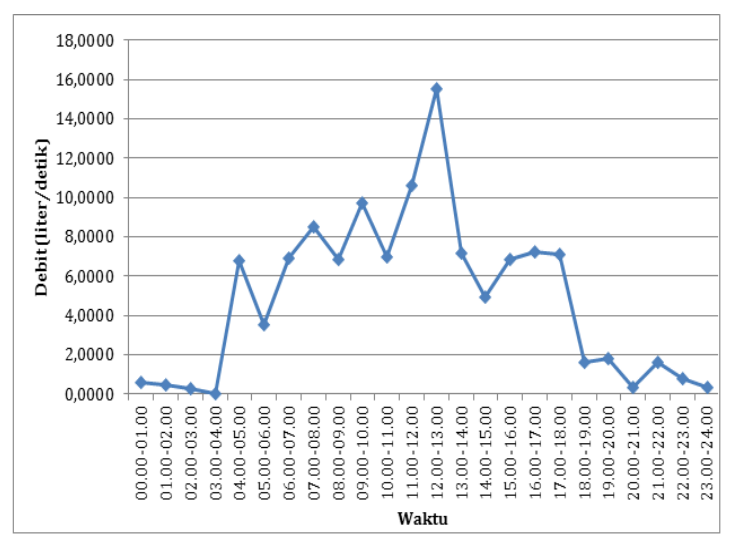

(a)

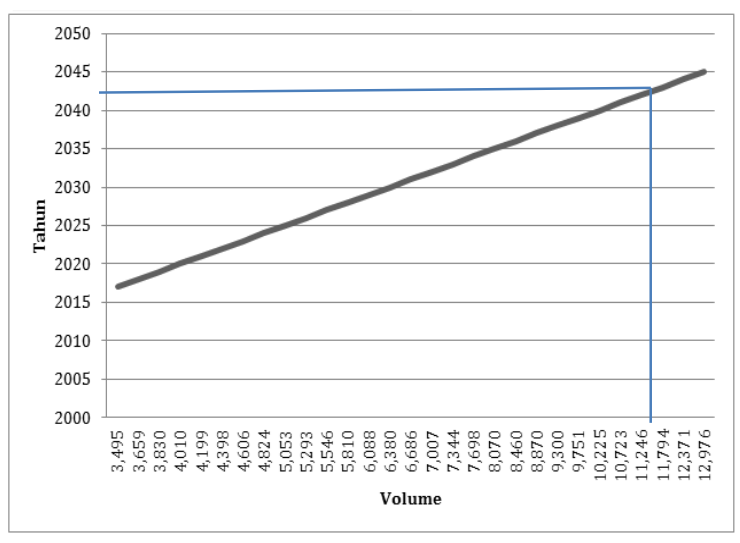

(b)

Gambar 3. (a) Fluktuasi Debit Air Buangan Cara Kuesioner (b),Contoh Grafik Perhitungan Umur Bak Pengumpul

Dari gambar 3(a) didapatkan bahwa debit air buangan rata-rata sebesar $0,004854 \mathrm{~m}^{3} /$ detik atau 4,854 liter/detik dan debit air buangan maksimal sebesar 15,06 liter/detik di pukul 12.00-13.00 ,serta debit air buangan minimal terjadi pada 0 liter/detik di pukul 03.00-04.00.

Dengan pertumbuhan masing-masing pengguna mahasiswa 5,123 \%,pertumbuhan warga 2,577 $\%$,pertumbuhan dosen 2,226\%,dan pertumbuhan karyawan 1,952\%. Dari perhitungan umur dengan cara kuesioner diatas didapat umur tiap-tiap bak adalah sebagai berikut.
a. Bak Pengumpul
: 23 tahun di 2040
b. Bak Ekualisasi
: 21 tahun di 2038
c. Bak Sedimen I
: 35 tahun di 2052
d. Bak Biofilter Anaerob
: 21 tahun di 2038
e. Bak Biofilter Aerob
: 21 tahun di 2038
f. Bak Sedimen II
: 35 tahun di 2052

Dari perhitungan diatas dapat disimpulkan bahwa umur IPAL Kawasan di UNS berdasarkan debit dari kuesioner tersebut adalah 21 tahun.

\section{Perhitungan Umur dengan Standar Pemakaian Air}

Perhitungan debit dari standar pemakaian air menggunakan cara sebagai berikut.

a. Debit non domestik mahasiswa

Jumlah Mahasiswa

Asumsi Kehadiran Mahasiswa Perhari

(a) : 32.612 orang

Asumsi Mahasiswa Pengguna Kamar Mandi

(b) : 42,617\%

Asumsi Kebutuhan Air Bersih

(c) $: 50 \%$

(d) : 20 liter/orang/hari

Q Non Domestik Mahasiswa (Qm)

: (a) $x$ (b) $x(\mathrm{c})$

: 1,6086 liter/detik

b. Debit non domestik dosen
Jumlah Dosen
(a) : 1.667 orang
Asumsi Kebutuhan Air Bersih(b) : 50 liter/orang/hari (SNI No 03-7065- 2005)
Asumsi Kehadiran Dosen
(c) : $85 \%$

Q Non Domestik Dosen (Qd)

: (a) $x$ (b) $x(\mathrm{c})$ 
c. Debit non domestik karyawan Jumlah Karyawan

Asumsi Kebutuhan Air Bersih

Asumsi Kehadiran Karyawan

(a) : 1.398 orang

(b) : 50 liter/orang/hari (SNI No 03-7065-2005)

(c) $: 100 \%$

Q Non Domestik Karyawan (Qk)

: (a) $x$ (b) $\times(\mathrm{c})$

: 0,80903 liter/detik

d. Debit domestik warga

Jumlah Warga

Asumsi Kebutuhan Air Bersih

(a) : 3.243 orang

(b) : 100 liter/orang/hari (Tabel 2.4)

Q Domestik Warga (Qw)

: (a) $x$ (b)

: 3,7535 liter/detik

Sehingga dapat diketahui debit air buangan peraturan adalah 5,5334 liter/detik. Hasil perhitungan umur dengan peraturan dapat dilihat pada Gambar 4.

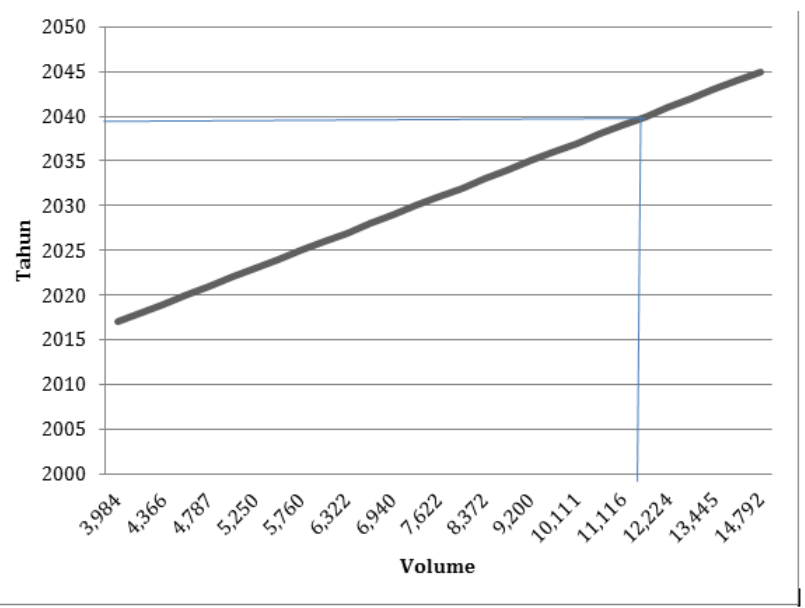

Gambar 4. Contoh Grafik Perhitungan Umur Bak Pengumpul

Dengan pertumbuhan masing-masing pengguna mahasiswa 5,123 \% , pertumbuhan warga 2,577 $\%$,pertumbuhan dosen $2,226 \%$, dan pertumbuhan karyawan $1,952 \%$. Dari perhitungan umur dengan peraturan diatas didapat umur tiap-tiap bak adalah sebagai berikut.
a. Bak Pengumpul
: 28 tahun di 2045
b. Bak Ekualisasi
: 26 tahun di 2043
c. Bak Sedimen I
: 26 tahun di 2043
d. Bak Biofilter Anaerob
: 12 tahun di 2029
e. Bak Biofilter Aerob
: 12 tahun di 2029
f. Bak Sedimen II
: 26 tahun di 2043

Dari perhitungan diatas dapat disimpulkan bahwa umur IPAL Kawasan di UNS berdasarkan debit dari peraturan tersebut adalah 12 tahun.

\section{KESIMPULAN}

Berdasarkan analisa data dan pembahasan dari hasil pengujian mengenai mengenai efisiensi kinerja,dan pengujian umur diperoleh beberapa kesimpulan sebagai berikut:

Berdasarkan analisis data dapat disimpulkan sebagai berikut. 
1. Debit air buangan dari pengukuran lapangan di outlet didapatkan debit air buangan rata-rata sebesar 3,0048 liter/detik sedangkan debit air buangan maksimal sebesar 12,195 liter/detik di pukul 01.00,dan debit air buangan minimal terjadi pada 0,9798 liter/detik di pukul 08.00.

2. Hasil pengujian laboratorium bagian inlet dan outlet IPAL Kawasan UNS adalah sebagai berikut.

\begin{tabular}{ccccc}
\hline \multirow{2}{*}{ No. } & Parameter & Satuan & \multicolumn{2}{c}{ Hasil Pengujian } \\
\cline { 4 - 5 } & & & Inlet & Outlet \\
\hline Parameter Fisika & & & \\
\hline 1. & Suhu & ${ }^{\circ} \mathrm{C}$ & 28,67 & 28,67 \\
\hline 2. & $\mathrm{TSS}$ & $\mathrm{mg} /$ liter & 62 & 29,33 \\
\hline \multicolumn{2}{r}{ Parameter Kimia } & & & \\
\hline 1. & $\mathrm{Ph}$ & - & 5,67 & 7 \\
\hline 2. & $\mathrm{BOD}_{5}$ & $\mathrm{mg} /$ liter & 35,416 & 9,044 \\
\hline 3. & COD Permanganat & $\mathrm{mg} /$ liter & 168,533 & 84,688 \\
\hline
\end{tabular}

3. Nilai efisiensi dari perhitungan data diperoleh nilai TSS yaitu 52,69 \% dan BOD sebesar 74,46 \% sedangkan untuk nilai COD Angka Permanganat sebesar 49,75\%. Dalam pengujian efisiensi tersebut hasil yang didapat sudah cukup baik tetapi tidak memenuhi desain kriteria IPAL UNS.

4. Debit air buangan rata-rata dari cara kuesioner sebesar 4,854 liter/detik sedangkan perhitungan debit buangan dari standar pemakaian air sebesar 5,5334 liter/detik.

5. Umur IPAL Kawasan di UNS berdasarkan debit dari kuesioner tersebut adalah 23 tahun pada 2041 dan umur IPAL Kawasan di UNS berdasarkan debit dari standar pemakaian air adalah 21 tahun pada 2038. Sedangkan perhitungan proyeksi air buangan dari konsultan IPAL berakhir di tahun 2037.

\section{REFERENSI}

Asmadi dan Suharno.(2012). Dasar-dasar Teknologi Pengolahan Air Limbah.Gosyen Publishing.Yogyakarta

Budi Supriyatno.(2000).Sistem Pengelolaan Air Limbah yang Berwawasan Lingkungan Suatu Strategi dan Langkah Penanganannya. http://www .kelair.bppt.go.id/Jtl/2000/vol1-1/03airlim.pdf, 30 April 2016.

Bambang Triatmodjo. (1993). Hidraulika I. Beta Offset : Yogyakarta.

Crites, Tchobanoglous. 2003. Small and Decentralized Wastewater Management Systems. McGrawHill:Singapore.

Dake,J.M. 1985. Essentials of Engineering Hydraulics Second Edition.

Departemen Pekerjaan Umum Direktorat Jenderal Cipta Karya.Kriteria Perencanaan Kebutuhan Air Limbah Domestik, 1996

Shokhikhul Irsyad.2005.Pedalaman Buku Teks Geografi. Yudhistira : Bogor.

Metcalf \& Eddy,Inc.1991.Wastewater Engineering:Treatment,Dispossal,Reuse 2rd ed.MsGraw-Hill Inc : New York.

Metcalf \& Eddy,Inc.2003.Wastewater Engineering:Treatment and Reuse Volume 2 Chapter IXXV.MsGraw-Hill Inc : New York.

Moh. Masduki Hardjosuprapto (MODUTO). 2000. Penyaluran Air Buangan (PAB) Volume II. ITB :Bandung.

Nyoman Wijana.2014.Imu Lingkungan edisi 2. Graha Ilmu : Yogyakarta. 
Qasim, Syed R. 1985. Wastewater Treatment Plant (Planning, Design, and Operation). CBS College Publishing:USA.

Rostina Sundayana.2015. Statika Penelitian Pendidikan.Alfabeta : Bandung.

V Wiratna Sujarweni.2014. Metodologi Penelitian.Pustakabaru press : Yogyakarta.

Fair,G.M.,Geyer, J.C.,and Okun,D.A.1971. Element of Water Supply and Wastewater Disposal Second Edition.John Willey and Sons, Inc : New York.

Guyton and Hall.2016. Textbook of Medical Physiology,Thirteenth Edition. John F. Kennedy Blvd : Philadelphia. 